\title{
EVIDENCE FOR OBLIGATE MONOPHENISM \\ IN RELIQUIA SANTAMARTA, \\ A NEOTROPICAL-ALPINE PIERINE BUTTERFLY \\ (LEPIDOPTERA:PIERIDAE)
}

\author{
BY ARTHUR M. SHAPIRO ${ }^{1}$ \\ Department of Zoology \\ University of California \\ Davis, California 95616, U.S.A.
}

\section{INTRODUCTION}

The phenomenon of seasonal polyphenism under photoperiodic control is now well established in a variety of butterflies, especially members of the family Pieridae (Shapiro, 1976a). Although it is expressed in nature primarily by multivoltine populations at low to middle altitudes in strongly seasonal mid-latitude climates, polyphenism has been found in a latent form in univoltine species which are ordinarily monophenic. These include species coevolved with vernal-ephemeral host plants (Pieris virginiensis Edwards, Shapiro, 1971; P. napi microstriata Comstock, Shapiro, 1975a) or facing short growing seasons due to altitude (Pieris occidentalis "calyce" Edwards, Shapiro, 1974) or latitude (P.o. nelsoni Edwards, Shapiro, 1975b). To date no population of either the Pieris callidice Hübner or $P$. napi Linnaeus complexes has been found to be obligately monophenic, although some $P$. napi (Yukon Territory and central New Mexico, Shapiro, 1976a) produce only more-orless heavily dark-veined phenotypes. The ability of univoltine Pierines to produce phenotypes analogous to normal seasonal ones produced by their multivoltine relatives, when reared in photoperiod-temperature regimes which do not occur in their natural habitat, has been interpreted (Shapiro, 1976a) as evidence for the derivation of univoltinism/monophenism from multivoltinism/polyphenism in the course of adaptation to new or changing climates.

\footnotetext{
${ }^{1}$ This work was made possible by grants from the National Geographic Society (USA) and the National Science Foundation (USA) and with the help of Colombian friends too numerous to mention. Special thanks go to Ms Adrienne R. Shapiro and Dr. Arthur S. Weston for their companionship and constant help afield in the Sierra Nevada.

Manuscript received by the editor December 15, 1977.
} 
Reliquia santamarta Ackery is an unusual Pierine of uncertain affinities which is known only from above $3500 \mathrm{~m}$ in the Sierra Nevada de Santa Marta of northeastern Colombia. It was discovered in 1971 and described four years later (Ackery, 1975). Phenotypically, the adult closely resembles high-altitude and -latitude members of the Holarctic Pieris callidice complex (figs. 1, 2) and is unlike the distinctive Andean montane and alpine Pierines (Tatochila, Phulia, Piercolias). In those genera the submarginal black chevrons on the hindwing above and below point outward in the interspaces. In Holarctic Pieris and in R. santamarta they point inward. Morphologically R. santamarta is also close to Pieris, and indeed would be included therein under the traditional broad concept of the genus, which is beginning to break down (Kudrna, 1974). These facts suggest that $R$. santamarta might represent a relict of a Holarctic stock of the $P$. callidice complex which invaded northern South America during a cold period, presumably in the Pleistocene. The Sierra Nevada de Santa Marta, although only $62 \mathrm{~km}$ from the Serrania de Valledupar which connects to the northern Andes, shows a very high degree of faunal and floral endemism. The entomologist who knows it best, Michael Adams, is convinced (1973, 1975, and personal communications) that its butterfly fauna had not begun differentiating before the eastern Andean orogeny - thus precisely contradicting the hypothesis of Todd and Carriker (1922) of an eastern Andean origin for the Sierran alpine avifauna - and that certain groups speciated and underwent character- and altitudinal displacement in the Pleistocene. A.S. Weston (personal communication) has noted a floristic connection between the Sierran páramos and those of Costa Rica. At least one butterfly, Nathalis iole Boisduval (Pieridae, Coliadinae) is perhaps a Nearctic relict in the Sierra Nevada de Santa Marta.

$R$. santamarta has been recorded from both dry seasons, the "verano" ("summer"; actually trade-wind season) in DecemberMarch and the shorter and less reliable "veranillo" in July - these being the only times of the year when weather conditions in the high Sierra would make butterfly collecting feasible. No phenotypic differences are apparent among the putative broods. This is perhaps not surprising. Pierines in middle latitudes respond phenotypically to daylength, but the Sierra lies at a latitude of $10^{\circ} 44^{\prime}$ $\mathrm{N}$, and the longest and shortest days of the year there differ in length by only about 70 minutes. The literature is devoid of photo- 
periodic studies of circumequatorial insects, except for one paper by McLeod (1968) who excluded photoperiod as a factor in the seasonal polyphenism of an African Nymphalid. If, however, $R e$ liquia santamarta were a Pleistocene derivative of the Pieris callidice complex, it might be expected to show a latent polyphenism when reared under a laboratory regime that induces light phenotypes in that group. Long days, particularly continuous light, coupled with high temperatures are very effective in this regard (Shapiro, 1976a).

\section{MATERIALS AND METHODS}

Eight females of $R$. santamarta were collected January 18-22, 1977 at and near the type locality (headwaters of the Río Cambirumeina and south slope of Cerro Icachui, 3950-4400 m). They were induced to oviposit in camp by confining them in sunlight in cylindrical tins $9.5 \times 10.5 \mathrm{~cm}$, covered outside with white glazed paper and topped with gauze, containing fresh sprigs of local Crucifers as oviposition substrates and Composite flowers as nectar sources. One female was a virgin, but all the others laid at least a few eggs. Eggs were placed on the plants, the gauze, and the tins. They were transported by ground to Valledupar, Department of Cesar, on January 26 and thence by air to Cali, Department of Valle del Cauca, the next day, where the first hatch occurred in the afternoon. Rearing was carried out in Cali on continuous light from a $60 \mathrm{w}$ bulb in plastic Petri dishes $18 \mathrm{~cm} \times 3 \mathrm{~cm}$ on fresh sprigs of the Crucifer Lepidium virginicum L. collected from a vacant lot; this common weed has often been used in experiments with Pierines and is a frequent wild host of North American members of the callidice group. The rearing temperature was $26.5^{\circ} \pm$ $2^{\circ}$ C. These conditions would induce light phenotypes in any Nearctic member of the callidice group which has been tested.

Due to electricity rationing in Colombia, it was necessary to substitute a powerful candle for the lamp from 1800 to 1900 hours daily throughout the rearing period. My impression, based on previous work with Pierines, is that this was read as "day" by the animals. Even if it was read as "night," a 23-hour photophase has always been read as a "long day" by Nearctic species.

$R$. santamarta proved difficult to rear under the experimental conditions in Cali. The culture started well, but about half the larvae died in the penultimate and ultimate instars of apparent 


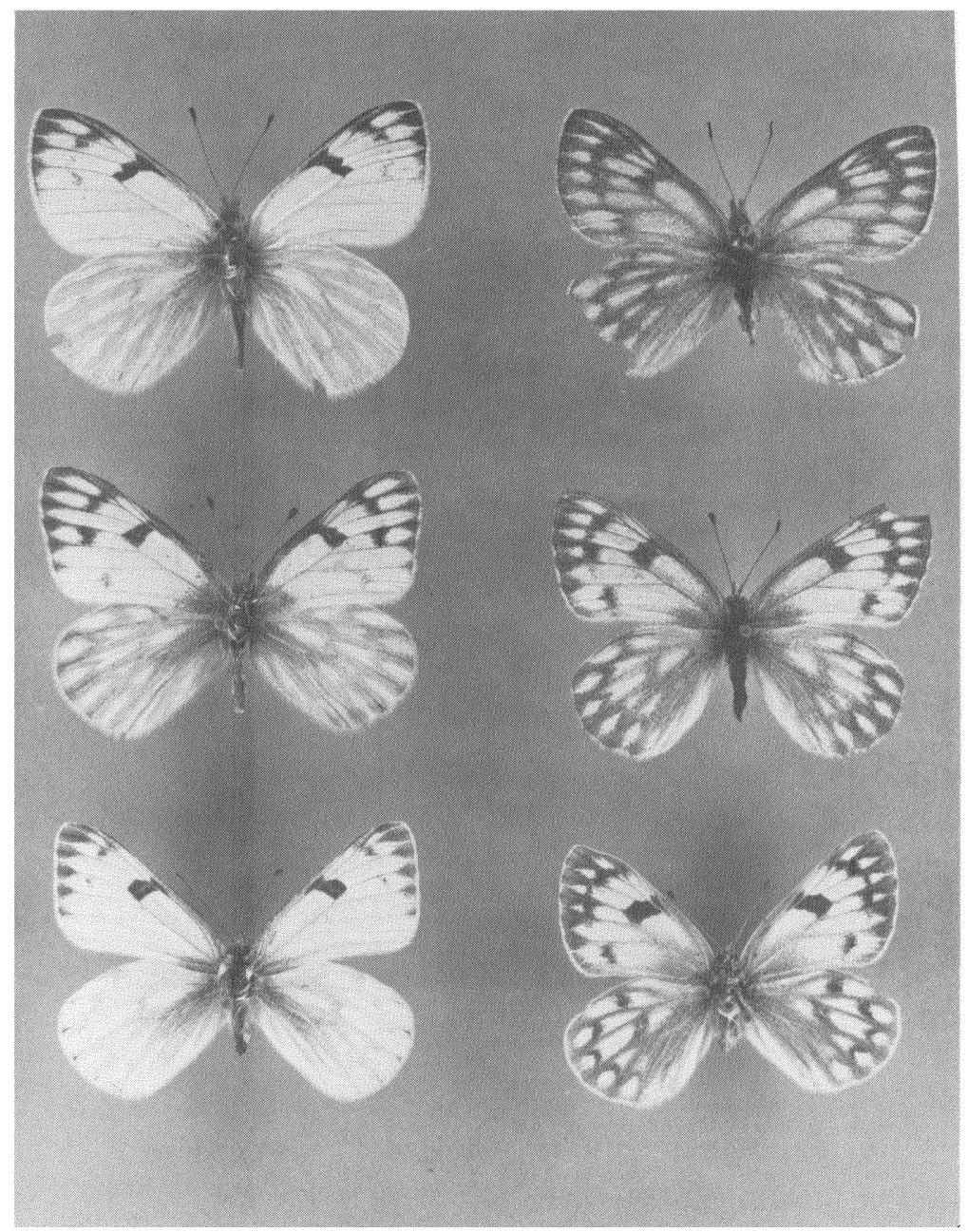

Figure 1. Dorsal surfaces of three Pierines from extreme climates, males at left. Top row: Reliquia santamarta, $4200 \mathrm{~m}$, Sierra Nevada de Santa Marta, Colombia, $10^{\circ} 44^{\prime} \mathrm{N}$. Centre: Pieris occidentalis "calyce," $3640 \mathrm{~m}$, Colorado front range, USA, $40^{\circ} 01^{\prime} \mathrm{N}$. Bottom: Pieris occidentalis nelsoni, Fairbanks, Alaska, $64^{\circ} 51^{\prime} \mathrm{N}$. 


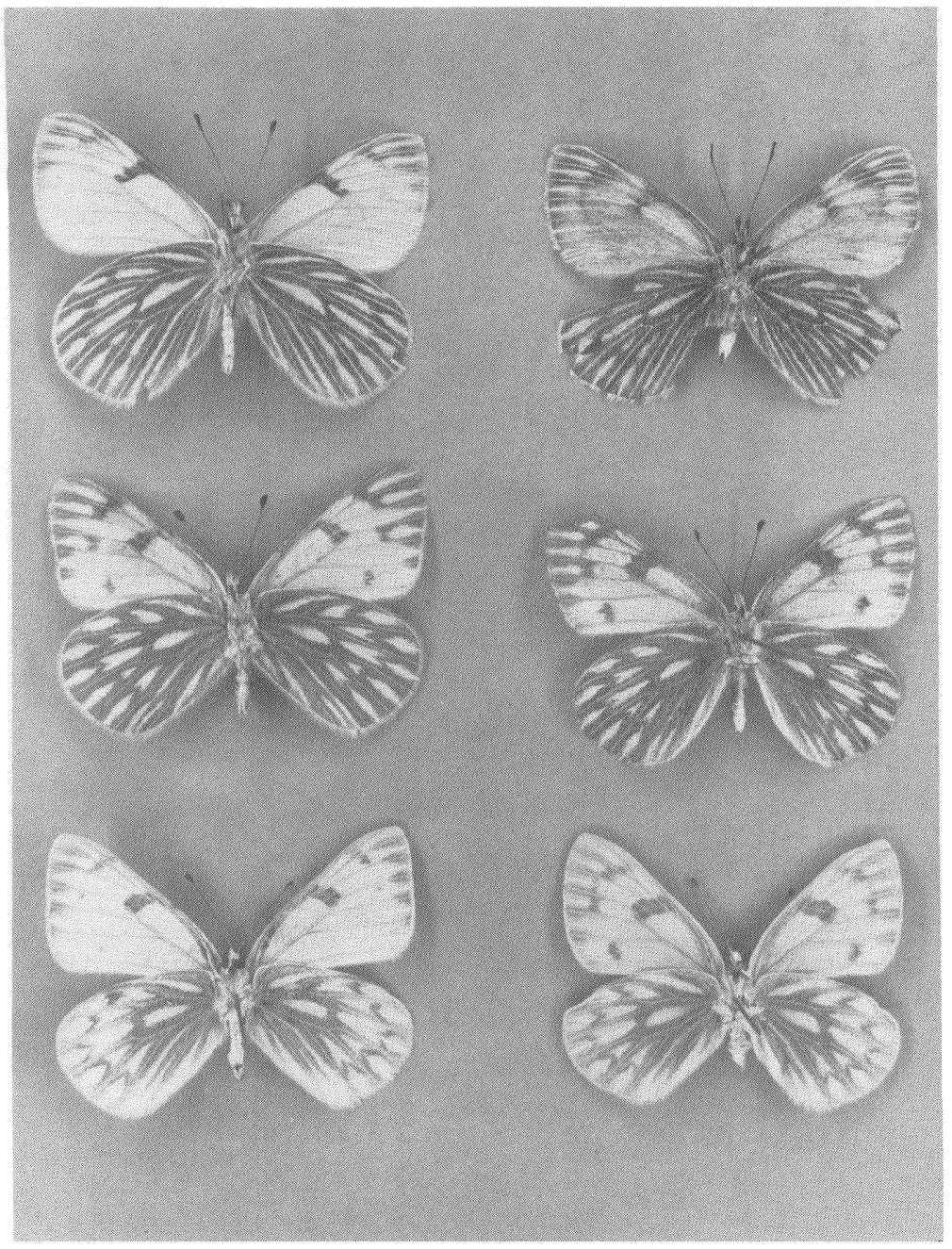

Figure 2. Same as figure 1, ventral surfaces. 
bacterial septicemia, despite stringent sanitation and daily replacement of the host plant. Ultimately 16 pupae were obtained, but 9 of these died without showing development. The remaining 7 pupae proceeded rapidly to the pharate adult, but failed to eclose. On February 15 they were all dissected to determine the phenotypes of the pharate adults - an easy and reliable procedure. Examples of the early stages were preserved and the life-history will be described elsewhere.

\section{RESULTS AND CONCLUSIONS}

All of the pharate adults ( 5 males, 2 females) were in good enough condition for the ventral hindwing phenotype to be determined (one female had to be degreased). All were completely normal, with the dark ventral pattern precisely as it occurs on wild specimens from the mountains.

Despite the small sample size, the use of the candle, and the overall logistical difficulty of the experiment, this is a definitive result since the phenotypes were so consistent and because no known Nearctic Pierine reared under the same conditions would have given the same result. Obviously we cannot exclude the possibility of a latent polyphenism, but it is made much less probable by the demonstration that it cannot be exposed under the most effective rearing regime known for that purpose. Since no Nearctic species yet tested has so canalized its phenotype, the likelihood that $R$. santamarta is a close relative of the species it most resembles is diminished.

Why lose the potential for polyphenism? There is no obvious selective advantage in doing so. In Holarctic populations it is merely submerged when selection for an appropriate phenology alters photoperiodic thresholds. This is especially easy in taxa in which phenotype is somehow coupled to pupal diapause, since all diapaused pupae will yield dark adults. We do not know if $R$. santamarta is capable of diapause; certainly it would make sense during the wettest months (October and November), but we do not know what the environmental cues might be. At any rate, the animals collected in January 1977 were in very mixed condition, suggesting overlapping broods during the "verano." As noted before no sign of seasonal phenotypes has been detected even though 
some of these adults would have been from diapause pupae if there are any such. We know from the experiment what non-diapause animals look like.

The dark-veined phenotype is undoubtedly optimal at all seasons at Cambirumeina. In the two dry seasons the normal weather is clear in the morning and foggy in the afternoon. Night temperatures drop below freezing; before the fog asserts itself the temperature may climb to $18^{\circ} \mathrm{C}$, but then it drops to $5-7^{\circ} \mathrm{C}$ and remains there until after nightfall, when clearing occurs. During my stay fog set in from 1000 to 1400 hours on different days, i.e. from 2 to 6 hours after the initiation of flight activity. This was at the sunniest time of the year; during the rainy seasons the temperature probably hovers between $2^{\circ}$ and $6^{\circ} \mathrm{C}$ most of the time, and sunshine occurs only fleetingly. The $R$. santamarta phenotype is of a sort known to be thermoregulatorily used by Nearctic Pierines (Shapiro, 1975c, 1976a) and the behavior of $R$. santamarta afield precisely matches theirs (Shapiro, 1977). Pieris occidentalis "calyce" Edwards in the Colorado front range has the same kind of weather during its flight season in August and matches R. santamarta in pattern, almost scale for scale. However, it retains a latent polyphenism (Shapiro, 1974, 1976b).

It is, of course, possible that the phenotype of $R$. santamarta is merely convergent to Pieris, and that no polyphenism has ever existed in its ancestry. If this is the case, the phylogeny of the Pierini is more confused than ever, and $R$. santamarta has no known close relatives.

\section{SUMMARY}

Reliquia santamarta is a multivoltine Pierine butterfly from above $3500 \mathrm{~m}$ in the Sierra Nevada de Santa Marta, Colombia, latitude $10^{\circ} 44^{\prime}$ N. Its single natural phenotype is extremely similar to the high-altitude and -latitude members of the Holarctic Pieris callidice complex. When reared on continuous light at $26.5^{\circ} \pm$ $2^{\circ} \mathrm{C}, R$. santamarta produced only its usual dark-veined, presumably thermoregulatory phenotype. In this regard it differs from all previously tested, Holarctic Pierines, which display latent polyphenism attributable to their evolution from multivoltine, phenotypically plastic ancestors. The seeming lack of a latent polyphenism in $R$. santamarta casts doubt on the close affinity of that animal to the $P$. callidice complex. Its relationships remain important for understanding the biogeography of the unusual endemic group of Andean Pierini. 


\section{REFERENCES}

ACKERY, P. R.

1975. A new Pierine genus and species with notes on the genus Tatochila (Lepidoptera: Pieridae). Bull. Allyn Mus. 30: 1-9.

Adams, $M$.

1973. Ecological zonation and the butterflies of the Sierra Nevada de Santa Marta, Colombia. J. Nat. Hist. 7: 699-718.

1975. Full report of the third "North Colombia Butterflies Expedition 1974/ 75". Mimeograph, $42 \mathrm{pp}$.

KUDRNA, O.

1974. Artogeia Verity 1947 gen. rev. for Papilio napi Linnaeus (Lep., PieriMCLEOD, L. dae). Entomol. Gaz. 25: 9-12.

1968. Controlled environment experiments with Precis octavia Cramer (Nymphalidae). J. Res. Lepid. 7: 1-18.

SHAPIRO, A. M.

1971. Occurrence of a latent polyphenism in Pieris virginiensis (Lepidoptera: Pieridae). Entomol. News 82: 13-16.

1974. Ecotypic variation in montane butterflies. Wasmann J. Biol. 32: 267280.

1975a. Developmental and phenotypic responses to photoperiod in uni- and bivoltine Pieris napi in California. Trans. R. ent. Soc. Lond. 127: 65-71.

1975b. Photoperiodic control of development and phenotype in a subarctic population of Pieris occidentalis (Lepidoptera: Pieridae). Can. Entomol. 107: 775-779.

1975c. Ecological and behavioral aspects of coexistence in six Crucifer-feeding Pierid butterflies in the central Sierra Nevada. Amer. Midl. Nat. 93: 424-433.

1976a. Seasonal polyphenism. in M. K. Hecht, W. C. Steere, and B. Wallace, eds., Evolutionary Biology, vol. 9, pp. 259-333. Plenum Press, New York and London.

1976b. Photoperiodic responses of phenologically aberrant populations of Pierid butterflies (Lepidoptera). Great Basin Nat. 35: 310-316.

1977. Notes on the behavior and ecology of Reliquia santamarta, an alpine butterfly (Lepidoptera: Pieridae) from the Sierra Nevada de Santa Marta, Colombia, with comparisons to Nearctic alpine Pierini. Studies in the Neotrop. Fauna Envt., in press.

TODD, W. E. C. AND M. A. CARRIKER, JR.

1922. The birds of the Santa Marta region of Colombia: a study in altitudinal distribution. Ann. Carneg. Mus. 14: 3-611. 

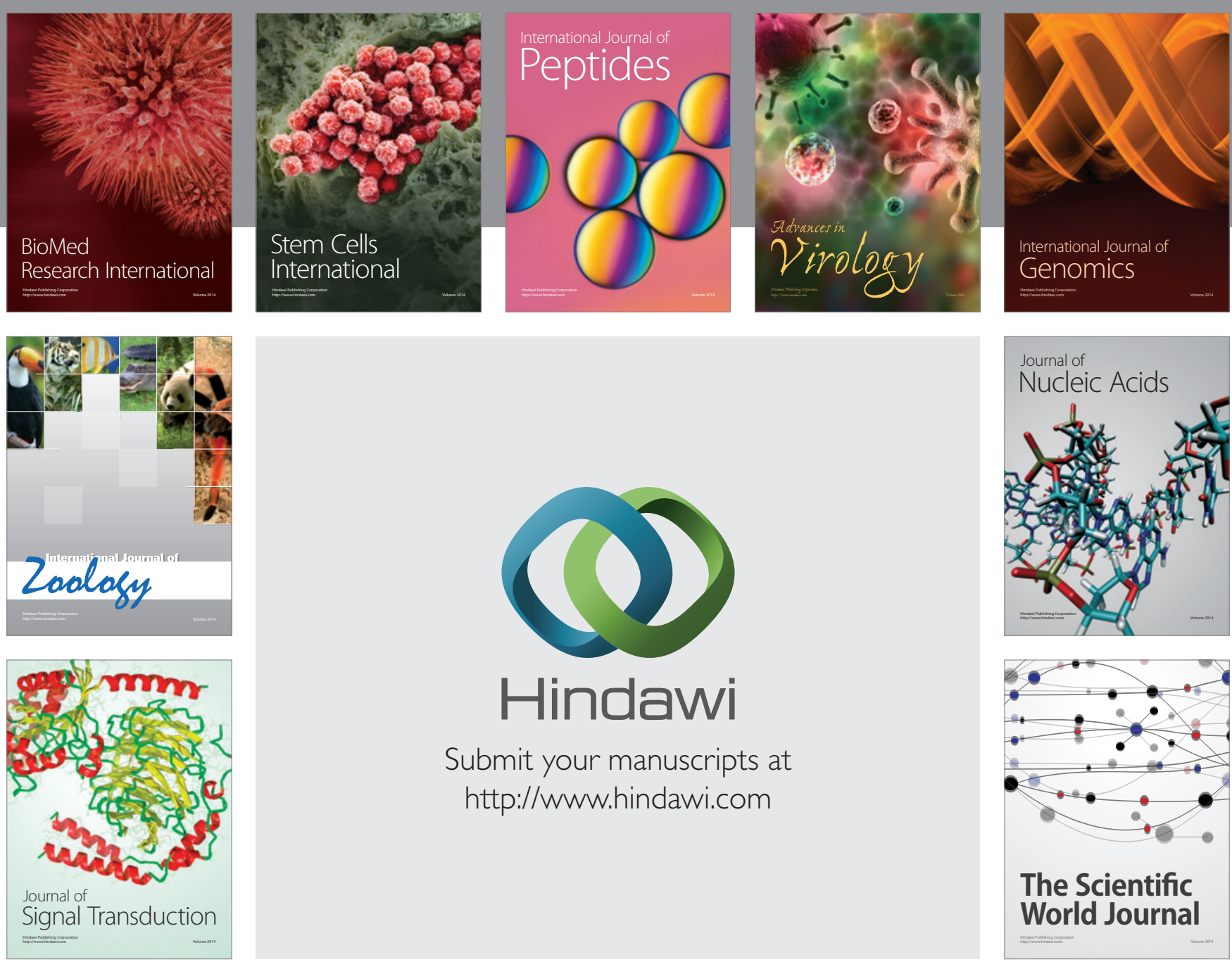

Submit your manuscripts at

http://www.hindawi.com
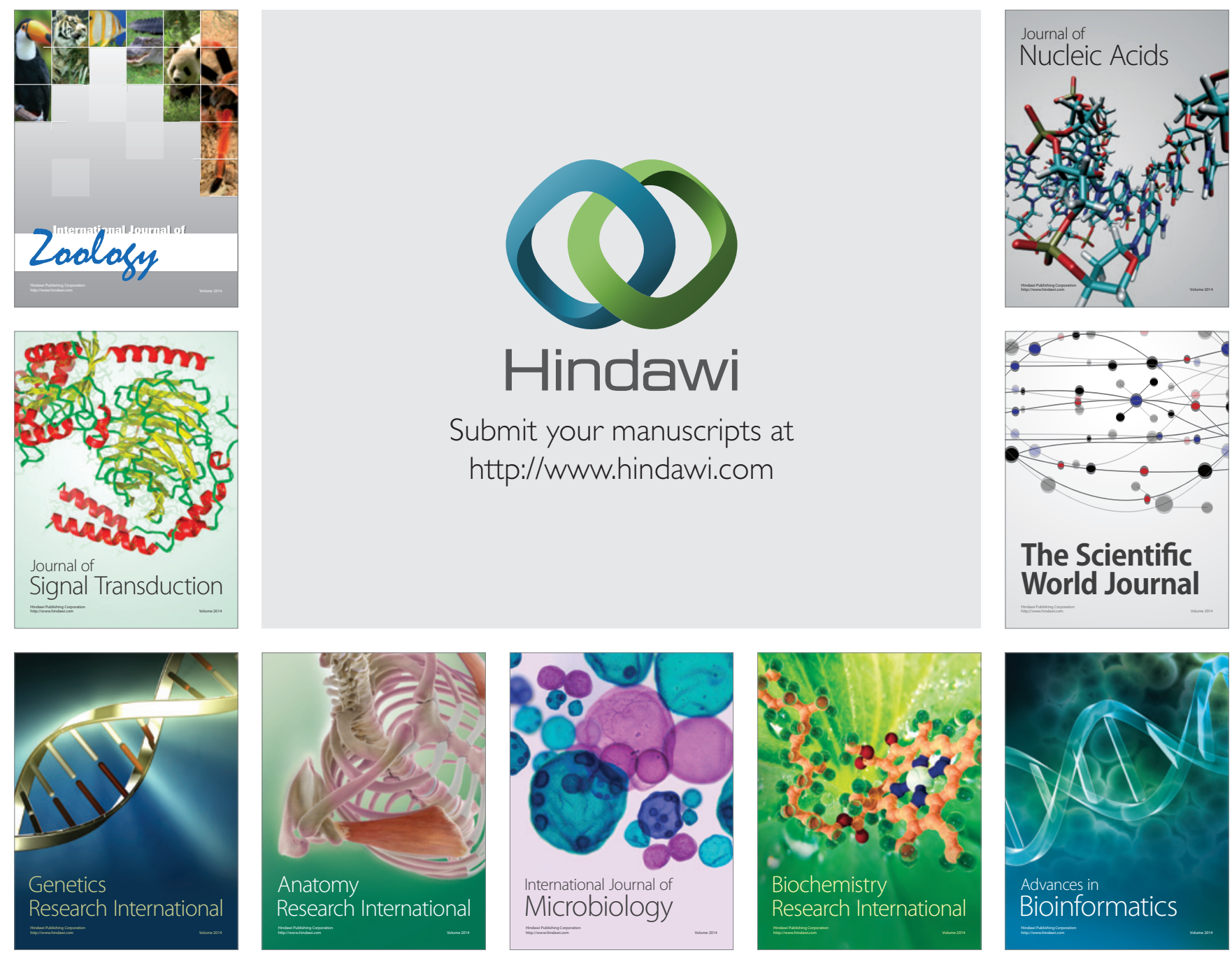

The Scientific World Journal
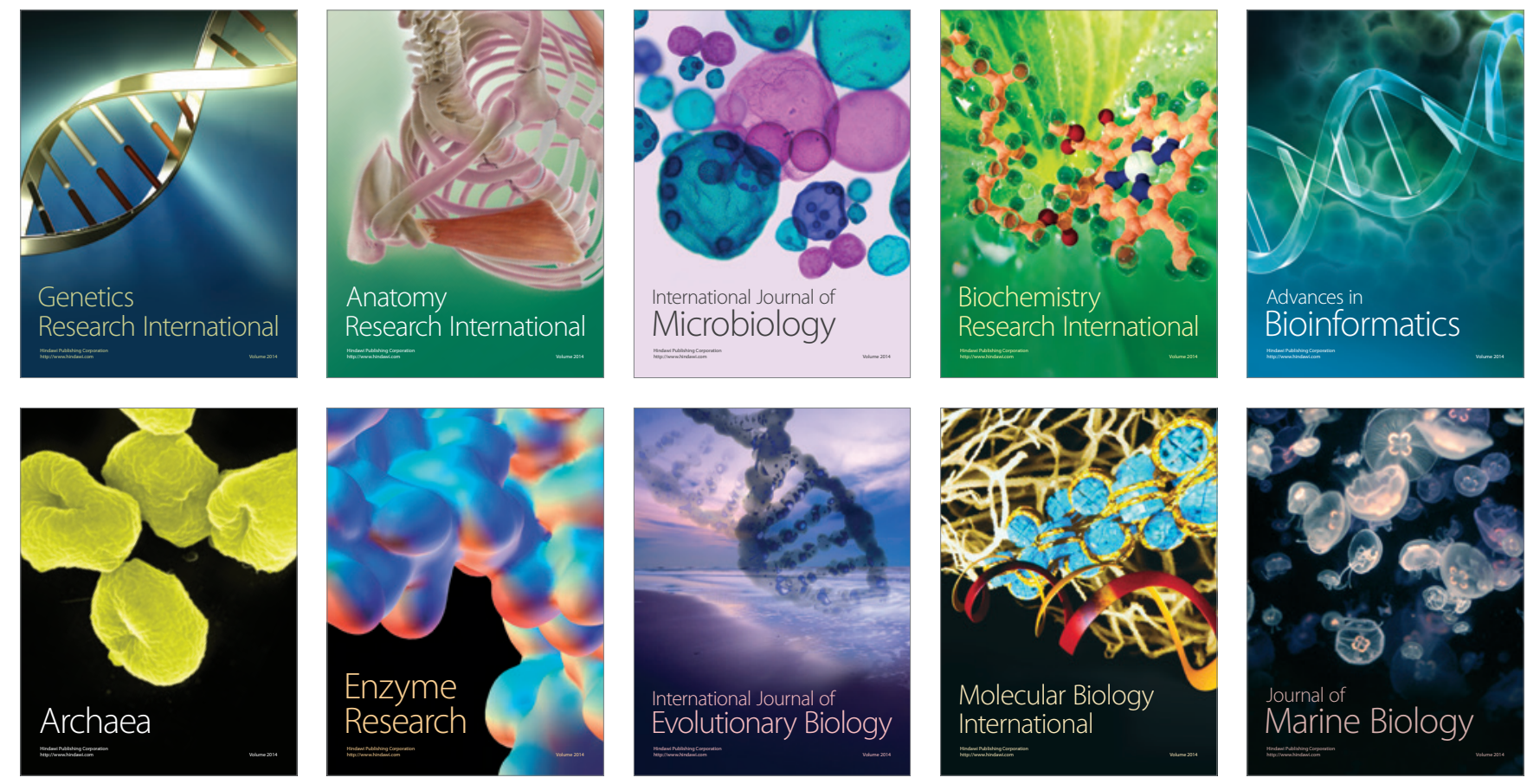